\title{
Intercambio de regalos entre la realeza europea y mercedes reales por servicios prestados a la corona (1621-1640)
}

\author{
Exchange of gifts between european royalty and royal gifts \\ for services rendered to the crown (1621-1640)
}

\author{
María del Carmen HEREDIA MORENO \\ Juana HIDALGO OGÁYAR † \\ Universidad de Alcalá de Henares
}

Recibido: 5-IV-2016

Aceptado: 6-VI-2016

Resumen: A partir del estado de la cuestión y a través de los datos inéditos que proporcionan los Libros de Paso entre 1621 y 1640, el artículo analiza los intercambios de regalos entre los miembros de la Casa Real española y sus parientes europeos. También recoge los obsequios que Felipe IV entregaba a los embajadores extranjeros después de concluir sus servicios en Madrid. Todo ello permite deducir el gusto suntuario de la aristocracia, el papel de los regalos para estrechar vínculos familiares, su importancia en el ámbito de la diplomacia y el contenido simbólico de algunos presentes.

Palabras clave: Regalos, Simbolismo, Lazos familiares, Felipe IV, Diplomacia, Gusto suntuario.

ABSTRACT: From the state of the question and through the unpublished data provided by Libros de Paso between 1621 and 1640, the article analyses the exchange of gifts between the members of the Royal House Spanish and their European relatives. Also it collects the gifts that Felipe IV gave to the foreign ambassadors after concluding his services in Madrid. This allows deduce the luxury taste of the aristocracy, the role of gifts to strengthen family ties, its importance in the field of diplomacy and the symbolic content of some presents.

Keywords: Gifts, Symbolism, Family ties, Felipe IV, Diplomacy, Luxury taste.

La entrega y el intercambio de regalos entre personajes de la aristocracia fue una costumbre muy arraigada desde la Antigüedad y se mantuvo en las cortes europeas a lo largo de toda la Edad Moderna, pero su puesta en práctica se regía por unas sutiles normas, a veces no escritas, que variaban en cada caso según el tiempo, lugar y circunstancias ${ }^{1}$. El buen uso de los regalos podía

${ }^{1}$ El presente artículo se ha elaborado en el marco del Proyecto de Investigación Construir y conservar lealtades colectivas. Soberanía y élites en la Monarquía de España (si- 
tener consecuencias positivas en el ámbito de la diplomacia, tanto para la obtención de condiciones favorables en la firma de tratados, como, en un terreno más personal, para obtener prebendas o ayudas en metálico y para facilitar el acceso a un cargo público civil o religioso. En suma, como dice Checa Cremades, los regalos eran un medio idóneo para conseguir favores y reconocimientos y para ganar voluntades ${ }^{2}$.

Para este historiador, tales prácticas están estrechamente vinculadas al coleccionis-mo y a la fiesta, factores ambos que adquirieron gran desarrollo en el reinado de Felipe III, como reflejó en su día el viajero y cronista portugués Pinheiro da Veiga al comentar las suntuosas almonedas que se celebraban en Valladolid o la espléndida recepción del duque de Lerma a los embajadores ingleses en el año $1602^{3}$. Checa considera que las fiestas eran los momentos más propicios para hacer regalos $\mathrm{y}$ trae a colación los que se ofrecieron al futuro emperador Carlos V con motivo de su bautizo en Gante en el año 1500, señalando su valor material y suntuario pero haciendo hincapié también en su carácter "emblemático y figurativo de futuras dignidades", como la celada de oro, la espada o las armas que le ofrecieron Carlos de Croy y otros nobles europeos ${ }^{4}$.

Por lo que concierne al siglo XVII español, las primeras aproximaciones generales a estas cuestiones tuvieron lugar en los coloquios de la villa Spelman celebrados en el año 1998 y en el congreso de la Casa de Velázquez de Madrid del 20025 . Entre los

glos XVI y XVII), Referencia: HAR2012-39016-C04-02, Secretaría de Estado de Investigación, Desarrollo e Innovación, Dirección General de Investigación y Gestión del Plan Nacional de I+D+i.

${ }^{2}$ F. CHECA CREMADES, "Regalos y obras de arte en las sociedades del Renacimiento y del Barroco", Revista de Occidente, nº 67, 1986, pp. 31-40.

${ }^{3}$ T. PINHEIRO DA VEIGA, Fastiginia. Vida cotidiana en la corte de Valladolid, Valladolid, 1989 (traducción y notas de Narciso Alonso Cortés).

${ }^{4}$ F. CHECA CREMADES, Op. cit., pp. 34-35.

${ }^{5}$ E. CROPPER, (coord.), The Diplomacy of Art: Artistic creation and politic in Seicento Italy, Florence, 2000 y J. L. muchos y variados asuntos que se trataron en dichas sesiones científicas, Goldberg, por ejemplo, consideró que los regalos eran la llave maestra que aseguraba el éxito de las misiones diplomáticas en la corte española. Se basa en las Relazione segreta de Orazio della Rena que permaneció doce años en España entre 1593 y 1605 como miembro de la delegación del Gran Duque de Toscana y resalta entre sus muchas advertencias un par de puntos ${ }^{6}$. En primer lugar, que el embajador debe regalar pero debe ser discreto y nunca publicar sus regalos. En segundo término, que los que demandan regalos son tantos, que los que se entreguen nunca serán suficientes.

Para Malcolm, los obsequios suponían una muestra de la liberalidad del donante y del aprecio del destinatario por las atenciones recibidas. En suma, un instrumento para establecer o consolidar lealtades, lazos de amistad y alianzas políticas ${ }^{7}$. No obstante puntualiza que rehusar un regalo en ciertos casos podía ser síntoma de honradez administrativa. A este respecto cita el reloj que John Werden, encargado de negocios de la embajada inglesa en Madrid en 1668, intentó ofrecer al secretario Pedro Fernández del Campo y que fue rechazado por este último.

También se prestó atención en las mencionadas reuniones científicas al intercambio de joyas, caballos, retratos en miniatura o aderezos de ámbar que tuvo lugar en la isla de los Faisanes en 1659 con motivo del doble enlace real entre España y Francia ${ }^{8}$.

COLOMER, (dir.), Arte y Diplomacia de la Monarquía Hispánica en el S. XVII, Madrid, 2003.

${ }^{6}$ E. GOLDBERG, "State gifts from the Medici to the court of Philip III", en J. L. COLOMER (dir.), Op. cit., pp. 115-133.

${ }^{7}$ A. MALCOLM, "Arte, diplomacia y política de la corte durante las embajadas del conde de Sandwich en Madrid y Lisboa (1666-1668)", en J. L. COLOMER (dir.), Op. cit., pp. 161-175.

${ }^{8}$ J. L. COLOMER, "Paz política y rivalidad suntuaria. Francia y España en la Isla de los Faisanes", en ÍDEM, Op. cit., pp. 61-88. 
Otros investigadores han tratado el tema de los regalos en los últimos años. Ma Cruz de Carlos se centra en la política y diplomacia que el VI Condestable de Castilla llevó a cabo por orden de Felipe III durante su estancia en Italia como gobernador de Milán y en la embajada extraordinaria de Inglaterra en 1604, subrayando, sobre todo, su papel en la supervisión y entrega de obsequios en nombre del rey con los que se quería reforzar los acuerdos políticos obtenidos tras la firma del Tratado de Londres ${ }^{9}$. En la misma fecha $M^{\mathbf{a}}$ Paz Aguiló insiste en el carácter del regalo como herramienta diplomática imprescindi$b e^{10}$. Desde esta perspectiva y partiendo de la consideración de la corte española como centro del lujo en el contexto europeo de la época de los Austrias, analiza la actuación de algunos embajadores y agentes artísticos, así como el intercambio de objetos devocionales con los nuncios y legados pontificios. Ambas autoras recogen el parecer de que "el dar es signo de superioridad, de ser más, de estar más alto, de magister y aceptar sin devolver o sin devolver más, es subordinarse, hacerse pequeño, transformarse en cliente y servidor, elegir lo más bajo...".

Carrió-Invernizzi estudió la conexión entre el poder y el canje de obsequios en el siglo XVII a través de ejemplos documentados del círculo de los embajadores españoles en la corte de Roma y en el entorno de los virreyes de Nápoles ${ }^{11}$. No obstante, advierte de que la elección de un regalo inapropiado al rango y categoría del destinatario o su entrega en un momento inoportuno podían volverse en contra del donante y producir

${ }_{9}^{9}$ M. C. de CARLOS, "Al modo de los antiguos. Las colecciones artísticas de Juan Fernández de Velasco, VI Condestable de Castilla", en B. ALONSO, M. C. DE CARLOS y F. PEREDA, Patronos y coleccionistas. Los Condestables de Castilla y el Arte (Siglos XV-XVII), Valladolid, 2005, pp. 207-277.

${ }^{10}$ M. P. AGUILÓ, “Lujo y religiosidad: El regalo diplomático en el siglo XVII", en Arte, poder y sociedad en la España de los siglos XV al XX, Madrid, 2008, pp. 50-62.

${ }^{11}$ D. CARRIÓ-INVERNIZZI, "Gift and diplomacy in seventeenth-century Spanish Italy", The Historical Journal, no 51, 2008, pp. 881-899. efectos contrarios a los objetivos inicialmente previstos. Esta misma tesis había defendido en 2005 García Pérez respecto al siglo XVI mencionando un expresivo párrafo de la Moral a Nicómaco de Aristóteles: "el hombre liberal y generoso dará porque es bello dar; y dará convenientemente, es decir, a los que debe dar, lo que debe dar, cuando debe dar, y con todas las demás condiciones que constituyen una donación bien hecha"12. Por su parte García Cueto analizó el papel que los virreyes de Nápoles jugaron en el envío de obras de arte y objetos suntuarios a la corte española ${ }^{13}$. A este respecto, los trabajos sobre José de Ribera han proporcionado mucha información sobre el mecenazgo artístico de estos personajes y la llegada a España de muchas de sus obras ${ }^{14}$.

Por lo que concierne a la utilización de los Libros de Paso que ahora tratamos, los estudios pioneros fueron los de Morán Turina en 1994 y de Alvar Ezquerra en 1996. El primero se interesó por las importaciones y exportaciones de pintura en el Seiscientos subrayando la importancia de estas fuentes para el conocimiento del arte de la época ${ }^{15}$, mientras que el segundo realizó una aproximación a los intercambios culturales entre Castilla y los Países Bajos durante el reinado

\footnotetext{
${ }^{12}$ N. GARCÍA PÉREZ, “Mencía de Mendoza y el intercambio de regalos: Una práctica obligada entre las elites de poder", en J. RIVAS CARMONA (coord.), Estudios de Platería San Eloy 2005, Murcia, 2005, pp. 157
} y 158 .

${ }^{13}$ D. GARCÍA CUETO, “Presentes de Nápoles. Los virreyes y el envío de obras de arte y objetos suntuarios para la Corona durante el siglo XVII", Nápoles y España. Coleccionismo y mecenazgo artístico de los virreyes en el siglo XVII. Madrid, 2009, pp. 293-322.

${ }^{14}$ Citamos como ejemplo A. E. PÉREZ SÁNCHEZ, Ribera (1591-1652), Madrid, 1992. A. E. PÉREZ SÁNCHEZ y N. SPINOSA, Jusepe de Ribera, el Españoleto, Barcelona, 2003. J. MILICUA, J. PORTUS y N. SPINOSA, Il giovane Ribera tra Roma, Parma e Napoli 1608-1624, Napoli, 2011-2012.

${ }^{15}$ M. MORÁN TURINA, “Importaciones y exportaciones de pintura en el siglo XVII a través de los Libros de paso", en Madrid en el contexto de lo hispánico desde la época de los Descubrimientos, Madrid, 1994, vol. I, pp. 543-561. 
de Felipe $\mathrm{II}^{16}$. Más allá del campo estricto de los regalos, pero con importantes aportaciones en este ámbito y con utilización puntual de algunos documentos de los Libros de Paso, hay que tener en cuenta varios estudios del año 1999 incorporados en el catálogo de la exposición sobre el arte en la época de los archiduques Alberto e Isabel Clara Eugenia que iremos citando a lo largo del texto ${ }^{17}$. En fechas más recientes, García García ha estudiado los obsequios diplomáticos a través de algunos ejemplos significativos recogidos de estos mismos documentos ${ }^{18}$. Este último historiador comienza su discurso citando emblemas de Alciato y de Sebastián de Covarrubias que avisan sobre los posibles peligros que conllevaban algunos regalos, porque "Los regalos de los enemigos son funestos"19, y que aconsejan que "Mire cada uno lo que recibe y de quién lo toma", que "No es don el don del enemigo... Los dones son tales del enemigo que so el bien dan males" 20 .

De cualquier forma, la cantidad de datos que proporcionan las licencias de paso permiten profundizar en su análisis y abordarlos desde diversos puntos de vista, como muestran recientes artículos sobre el transporte de obras suntuarias entre ambos lados de la frontera portuguesa ${ }^{21} \mathrm{o}$ sobre donacio-

${ }^{16}$ A. ALVAR EZQUERRA, "Los intercambios culturales entre los Países Bajos y Castilla en tiempos de Felipe II: un muestreo de las "Cédulas de Paso", Indagación. Revista de Historia y Arte, no 2, 1996, pp. 92-109.

${ }^{17}$ A. VERGARA (com.), El Arte en la Corte de los Archiduques Alberto de Austria e Isabel Clara Eugenia (15981633), Madrid, 1999-2000.

${ }^{18}$ B. J. GARCÍA GARCÍA, “Regalos diplomáticos y bienes suntuarios en la Corte española (1580-1665)", en Materia Crítica. Formas de ocio y de consumo en la cultura áurea. Biblioteca Áurea Hispánica, nº 58, 2009, p. 217.

${ }^{19}$ S. SEBASTIÁN, Emblemas de Alciato, Madrid, 1985, pp. 209-210, emblema CLXVII.

${ }^{20}$ J. de D. HERNÁNDEZ MIÑANO, Emblemas morales de Sebastián de Covarrubias. Iconografía y doctrina de la Contrarreforma, Murcia, 2015, p. 180.

${ }^{21}$ C. HEREDIA MORENO y J. HIDALGO OGÁYAR, "El transporte de artes suntuarias entre España y Portugal (1621-1640)", en prensa. nes de plata labrada a instituciones religio$\operatorname{sas}^{22}$. Por ello, el análisis que nos proponemos realizar ahora sobre el intercambio de regalos y sobre las mercedes reales durante los primeros veinte años del reinado de Felipe IV a partir de las noticias suministradas por estas fuentes, puede aportar noticias interesantes y aspectos inéditos sobre todas estas cuestiones. No obstante, hay que recordar que muchas de las licencias estaban protegidas por disposiciones reales, de manera que no se podían "abrir, catar ni escudriñar", circunstancia que impide conocer su contenido. Además, hay que tener en cuenta que la mayoría de los enseres que circulaban por las aduanas han desaparecido, bien por su carácter efímero bien por los cambios del gusto o de moda, bien porque sus ricos materiales o su alto precio los convertían en objetos idóneos para transformarlos en dinero líquido, en caso de necesidad, o en objeto de rapiña, en momentos de guerra. A pesar de todo ello, se tratará de efectuar una aproximación a estos regalos a través de lo poco conservado y de algunos testimonios indirectos.

La costumbre de hacer obsequios en el ámbito familiar de la realeza parece guiarse por normas amparadas en la tradición y de acuerdo con la calidad de los sujetos implicados. El Rey y sus parientes masculinos, además de caballos y jacas, solían ofrecer y recibir armaduras y armas de todo tipo y materiales, piezas de plata, joyas y pinturas. Por el contrario, los miembros femeninos de la familia real preferían intercambiar objetos de carácter devocional como esculturas religiosas, libros o rosarios, arquetas, joyas, cosas de olor, guantes de ámbar, cajas, flores, pájaros, juguetes y todo tipo de menudencias, además de pinturas, tapices y otras piezas suntuarias ${ }^{23}$.

22 ÍDEM, "De lealtades, donaciones y devociones: platería religiosa en las cédulas de paso de 1621 a 1640", en J. RIVAS CARMONA (coord.), Estudios de platería San Eloy 2015, Murcia 2015, pp. 199-212.

${ }^{23}$ Según los documentos que hemos manejado, el ámbar era una sustancia de obligada presencia en los equipajes de los viajeros y en los intercambios famili- 
Por lo tanto, aparte de alhajas, piezas artísticas y enseres muy costosos por su valor material o representativo, por su interés para el coleccionismo o por su calidad, se prodigaban y se tenían también en mucha estima las piezas exóticas como los biombos, porcelanas y objetos de nácar o de concha de tortuga y todo tipo de juguetes y de menudencias, incluso dulces y otros productos alimenticios que, más allá de su precio, se entendían como "detalles" fruto del cariño entre las partes. En suma, pequeños recuerdos que servían para estrechar afectos y lealtades familiares por encima de los vaivenes de la política, porque, como subraya Sebastián López, hay que "estimar en mucho los regalos de los amigos aunque sean de poco valor"24. A afianzar estos vínculos contribuían también los retratos de los reyes, príncipes o infantes que, además de su interés en el ámbito de la pintura y del coleccionismo, se utilizaban para explicitar el poder del retratado, como recordatorio o evocación del

ares. Pero en los casos que tratamos, el término no se refiere a la conocida resina fósil sino al ámbar gris que, según la RAE, "es una sustancia que se encuentra en las vísceras del cachalote, sólida, opaca de color gris con vetas amarillas y negras, de olor almizcleño, que al calor de la mano se ablanda como la cera, y la cual se halla en masas pequeñas y rugosas, sobrenadando en ciertos mares, especialmente en las costas de Coromandel, Sumatra y Madagascar. Se emplea en perfumería y como medicamento excitante". En todo caso, en la época de Felipe IV se utilizaba como sustancia aromática para aderezar guantes, bolsos, cordobanes y otros enseres. El Tesoro de la Lengua Castellana o Española compuesto por el licenciado Don Sebastián de Cobarruvias Orozco..., publicado en Madrid en 1611 (edición facsímil de Martín de Riquer, Barcelona, 1887), pp. 110-111, define el ámbar como "Una pasta de suavissimo olor, tan estimado como a todos es notorio, pues se vende por onças, y la onça en buenos ducados; no acabando los que escriben della de afirmarse de cierto que sea, porque unos tienen que es un excremento de la vallena, otros que su esperma y no pocos afirman ser un género de betún líquido que mana en lo profundo del mar, y por ser liviano sube a la superficie del agua y se quaja y las olas suelen echarlo a las orillas del mar adonde se halla. Uno llaman blanco, otro gris y otro ámbar negro...".

${ }^{24}$ S. SEBASTIÁN LÓPEZ, Op. cit., p. 210, recoge esta cita de A. RODRÍGUEZ MOÑINO, Virgilio en España. Ensayo bibliográfico sobre las traducciones de Diego López, 1600-1721, Badajoz, 1930. familiar ausente o como una primera ocasión para conocer su aspecto con vistas a un futuro enlace matrimonial. Los embajadores que volvían a sus estados se solían encargar de transportar estos retratos que contribuían además a difundir las obras y el estilo de determinados maestros por las cortes europeas.

Las cédulas de paso entre 1621 y 1640 ofrecen numerosos ejemplos de todas estas variables $^{25}$. A lo largo de estos veinte años, el propio Felipe IV estuvo involucrado en esta costumbre de intercambiar regalos entre sus parientes y recibió importantes obsequios de sus tías, las infantas Margarita y, sobre todo, Isabel Clara Eugenia. Isabel se había quedado viuda y sin herederos en el año 1621, y había tenido la intención de retirarse al Monasterio de Las Descalzas Reales, como sus predecesoras Margarita de Austria y María de Hungría, pero continuó desempeñando su papel en la corte de Bruselas a ruegos de su sobrino con el que mantuvo continuos contactos e intercambios de regalos, si bien en 1622 ingresó en la Orden Tercera de San Francisco ${ }^{26}$. Estas relaciones constan desde el año 1624, cuando el Rey le envió varias alfombras y almohadas más una docena de sillas turcas de cuero con franjas bordadas de oro y seda de colores ${ }^{27}$. Como contrapartida, Isabel regaló al monarca sendos juegos de armería en 1624 y en 1626. El documento de 1626 detalla que "La infanta doña Isabel, mi tia, me ha enviado de Flandes cuatro

\footnotetext{
${ }^{25}$ Ante la imposibilidad de transcribir todos los documentos debido a su elevado número o a la extensión de algunos, hemos hecho una selección para dar una idea de la variedad de los mismos en cuanto a los personajes implicados, la gran cantidad de productos objeto de regalo y la diversidad de funciones que cumplían en el contexto de la época.

${ }^{26}$ Sobre estas cuestiones y sobre la manera que tenían las mujeres gobernadoras de la Casa de Austria de legitimar su poder a través de las joyas, véase N. GARCÍA PÉREZ, "Joyas y legitimación de poder en las mujeres gobernantes del Renacimiento", en J. RIVAS CARMONA (coord.), Estudios de platería...2015, pp. 175-182.
}

${ }^{27}$ Archivo Histórico Nacional (en adelante AHN), Consejos, Libro de Paso 635, fols. 152v.-153r. 
cuerpos de armas dorados, plateados y granados, los dos de acaballo y los otros dos de a pie, 6 trineos de diferentes hechuras con seis guarniciones cumplidas para seis caballos, seis penachos grandes para las texteras de dichos caballos y otros seis mas pequeños para los cordones, todo dentro de 16 caxas cubiertas de encerado verde a cargo de Antonio de Mendoza, veedor y contador de la infanta" 28

Ambos lotes se documentaron tam-bién a través de un inventario de 1625-31 del archivo del Palacio Real y se conservan hoy incompletos en la Real Armería de Madrid ${ }^{29}$. A su funcionalidad práctica de carácter bélico añaden la riqueza de sus materiales (acero, oro, cuero y plata), una apreciable calidad técnica y unos diseños sencillos y elegantes recubiertos de una sofisticada decoración, de innegable valor estético ${ }^{30}$. Las armaduras de 1624 son obras flamencas de un autor de posible origen francés conocido como "el maestro del $\mathrm{MP}^{\prime \prime}$ y sus celadas incorporan el monograma de "Ysabel" bajo corona real, posible alusión a la donante Isabel Clara Eugenia o a la reina Isabel de Borbón, primera esposa de Felipe IV. Las de 1626, también flamencas pero de autor anónimo, sobrepasan a las anteriores por su decoración más profusa y variada de follajes. Dos de estas últimas las regaló el monarca a don Juan José de Austria y al margrave Federico Darmstadt.

Recordemos que en la primera mitad del siglo XVII las armaduras de guerra habían perdido parte de su importancia a causa del progresivo perfeccionamiento de las armas de fuego. Sin embargo conservaron su carácter representativo como símbolo del poder y autoridad real, al tiempo que sus materiales y su calidad técnica y artística las

\footnotetext{
${ }^{28}$ Ibídem, fols. 324 r.-326r.

${ }^{29}$ A. SOLER DEL CAMPO, "La real Armería de Madrid", Arbor, no 665, 2001, pp. 153-154.

${ }^{30}$ Algunas piezas se exhibieron en la exposición de 1994 y fueron analizadas prolijamente por ÍDEM, "Armaduras de Felipe IV. El regalo de 1624" y "Armaduras de Felipe IV. El regalo de 1626", en A. VERGARA (com.), Op.cit., pp. 194-201, nºs. 41-42.
}

convertían en objetos de lujo y de coleccionismo muy codiciados. De ahí el gran interés de estas piezas.

Un par de años después de su entrega, el pintor flamenco Pedro Pablo Rubens llegó a Madrid con ocho cuadros de asunto histórico y mitológico que se instalaron en el Salón Nuevo del Alcázar. De ellos se conservan La reconciliación de Jacob y Esaú (Alte Pinakhotek de Múnich), Sansón y el león (Colección particular madrileña) y Ninfas con el cuerno de la abundancia (Museo del Prado). Alejandro Vergara sugiere que pudieron ser un encargo de la propia Isabel Clara Eugenia como regalo para su sobrino y como presentación del artista en la corte españo$\mathrm{la}^{31}$. En todo caso, como posible respuesta a estos obsequios, cuando el maestro regresó a Flandes a finales de abril de 1629, llevaba diversos presentes para Isabel de parte de los reyes de España: “El Rey. A nuestro capitán de la provincia de Guipúzcoa. Sabed que Pedro Pablo Rubens va a los nuestros estados de Flandes y lleva una docena de pinturas en lienzo y láminas, dos caxetas con piedras antiguas y una joya sortija de diamantes..." 32 .

Algunas de estas pinturas pueden identificarse con los retratos reales de Velázquez de medio cuerpo que hoy se localizan en diversos museos europeos y americanos ${ }^{33}$. Dos años más tarde, Isabel remitió a la Corte de Madrid unos obsequios de contenido muy variado, debido a la diversidad de los destinatarios, a saber: "La serenisima infanta doña Isabel, mi tia, embia para mi servicio y el del serenísimo principe ${ }_{\iota}$ mi muy caro y amado hijo, y infanta doña Margarita, mi tia, las cosas siguientes: 7 paños de tapiceria, 74 cuerpos de breviarios, 33 diurniales, una caxa pequeña sobreescrita doña Ana Doro-

\footnotetext{
${ }^{31}$ Vid. ÍDEM, "La pintura en el ámbito de los archiduques", en ÍDEM (com.), El arte en la corte de los archiduques..., pp. 79-80.

${ }^{32}$ AHN, Consejos, Libro de Paso 636, s/fol.

${ }^{33}$ Sobre la problemática de estas pinturas puede consultarse A. VERGARA, “La pintura en el ámbito de los archiduques", en ÍDEM (com.), El arte en la corte de los archiduques..., pp. 80-81 y 278 no 95.
} 
tea, marquesa de Austria, dos caxas pequeñas en que vienen unos jardinicos, una caja redonda para doña Beattriz de la Concepion, carmelita descalza en Salamanca, una pintura sobreescrita a Francisco Manza-no, 33 linternas, unos envoltorios con colores y pinceles de pintar al agua, un envoltorio para Beatriz de la Concepcion, dos caxas, una ancha y redonda con flores para la señora infanta, muchas cajas pequeñas con Niños Jesus de cera, cesticas y caxuelas con pajaros y otras cosas de Alemania, y algunos rosarios, cestas, estampas y otras cosas de devocion, diferentes juguetes de Alemania, un cavallero, dos caxas una con un baquerillo y la otra con espada y daga, una figurilla de cera que toca el laud, un escritorio de ebano que tiene por remate una danza de figurillas de Alemania, un Niño de cera en la cuna y tres potecillos con flores de oro, una pintura grande para mi y otras para la dicha doña Ana Dorotea"34.

Es decir, en este caso predominan los libros, figuras de cera y objetos de devoción, juguetes de Alemania, flores y otras variadas menudencias. De escuela flamenca y de cierta calidad podría ser la pintura de gran tamaño destinada al Rey, pero el documento no recoge su temática ni su autoría.

Los presentes intercambiados entre Felipe IV y el infante don Fernando en el año 1633 fueron de naturaleza muy distinta: "Al infante cardenal, mi hermano algunas joyas de oro y diamantes, cadenas y medallas para la jornada de Flandes" ${ }^{\prime 35}$. El cardenal viajaba en estos momentos a Bruselas para hacerse cargo del gobierno de los Países Bajos como sucesor de Isabel Clara Eugenia y el viaje se había preparado cuidadosamente desde Madrid con mucho tiempo de antelación, puesto que ya el año anterior Juan Gómez de Mora, maestro de obras y aposentador real, se había desplazado a Valencia para "hacer el aposento para el rey y para los infantes" ${ }^{36}$.

${ }^{34}$ AHN, Consejos, Libro de Paso 636, fol. 162v. y sigueintes.

${ }^{35} \mathrm{Ibídem}$, fol. 260r.

${ }^{36}$ Ibídem, fol. 212r.
Por lo tanto, el carácter excepcional de la ocasión justificaba la naturaleza de estos obsequios que contribuirían a la buena imagen del cardenal durante la ceremonia de su entrada oficial en la corte flamenca, ya que debía escenificar en su persona, con el mayor boato posible, la grandeza y el poder del monarca al que representaba. La propia reina, Isabel de Borbón, contribuyó a esta empresa remitiendo a su cuñado un par de escritorios de ébano guarnecidos de plata repletos de guantes de ámbar y cosas de olor, botones y presillas de oro y un par de rosarios de ámbar con extremos y cruces de oro y diamantes ${ }^{37}$. Por su parte, don Fernando correspondió generosamente a estos regalos con costosos envíos que llegaron a la Península a finales de marzo de 1633: "Juan Castellanos, palafrenero del cardenal infante, mi hermano, vino por su orden y trae para mi servicio (del Rey) por orden de su alteza lo siguiente: 12 arcas grandes cubiertas de encerado verde que en las once hay veintidos sillas bordadas de oro y plata de diferentes colores con todos sus aderezos cumplidos, en la otra caja hay seis telleces bordados de oro y plata ricos y dos pistolas de oro esmaltadas, tres sillas de terciopelo negro con pasamanos en sus cajas con sus aderezos de cuero, 21 cajas con otras tantas sillas de cuero pardillo con sus aderezos de cuero y 47 caballos y jacas" ${ }^{\prime 38}$.

A comienzos del año siguiente don Fernando remitió otras diez cajas y cofres con diferentes cosas para el servicio de los reyes, además de "una aca (jaca) para el serenisimo principe Baltasar Carlos" ${ }^{39}$. Espléndidos fueron también los regalos que mandó para su hermano y para su sobrino en el año 1637, que incluían treinta y dos caballos, varias tiendas de campaña, un par de carrozas, ocho esculturas, una tapicería y un reloj ${ }^{40}$. Por último, los regalos intercambiados entre

\footnotetext{
${ }^{37}$ Ibídem, fol. 276r.

${ }^{38}$ Ibídem, fol. 263r.

${ }^{39} \mathrm{Ibídem}$, fol. $297 \mathrm{v}$.

${ }^{40}$ J. B. GARCÍA GARCÍA, Op. cit., pp. 239-240.
} 
ambos hermanos se documentan también en el año 1639 por cartas del Cardenal Infante en que informa al monarca español sobre el retrato que le está terminando su pintor de cámara Gaspar de Crayer para enviárselo a la corte de Madrid. También le indica que el del príncipe Baltasar Carlos realizado por Velázquez se encontraba ya en su poder. El primero, que se guarda hoy en el museo del Prado, presenta al infante de cuerpo entero vestido con hábito cardenalicio ${ }^{41}$. Debió ser del agrado del monarca, puesto que Felipe ofreció a Crayer una medalla y una cadena de oro $^{42}$. El segundo reproduce al príncipe también de cuerpo entero, de pie y de edad de unos diez años. Fue el último que le pintó Velázquez, ya que a partir de entonces su retratista oficial sería Juan Bautista Martínez del $\mathrm{Mazo}^{43}$. El original o una copia se localizan en el Kunsthistoriches Museum de Vie$\mathrm{na}^{44}$.

Por lo tanto, aparte de las cajas y cofres, sobre las que no se indica su contenido, parece que el Cardenal Infante gustaba de regalar pinturas, coches, armas, tiendas de campaña, guarniciones de caballerías y caballos. Es decir, enseres y animales para la caza o para la guerra, piezas artísticas y objetos de carácter representativo del poder real. Ante la imposibilidad de localizar estos otros obsequios, nos acercaremos a ellos de manera indirecta.

Los coches y demás vehículos de la época, excepto las sillas de mano, eran estructuras de madera y de cuero, de tracción animal, tapizadas con ricos textiles, cuya rapi-

${ }^{41}$ M. DÍAZ PADRÓN, El siglo de Rubens en el Museo del Prado, Madrid, 1995, p. 390.

42 Sobre la actividad de Crayer como retratista puede consultarse ÍDEM, "Gaspar de Crayer un pintor de retratos de los Austrias", Archivo Español de Arte, no 151, 1965, pp. 229-244.

${ }^{43}$ F. CHECA CREMADES, Velázquez. Obra completa, Barcelona, 2008, p. 303.

${ }^{44}$ J. LÓPEZ REY, Velázquez, Colonia, 1996, Vol. II, nº 90. En cambio, J. M. CRUZ VALDOVINOS, Velázquez. Vida y obra de un pintor cortesano, Zaragoza, 2011, p. 227, lo considera copia del enviado a Bruselas. dez, lujo y confort para los desplazamientos explicitaba la riqueza, el poder y el estatus de su dueño, de manera que con frecuencia fueron objeto de "regalos principescos". En el ámbito real formaban parte esencial de la caballeriza y se utilizaban para el transporte, partidas de caza y ceremonias oficiales de la Corte. En estas últimas asumían un profundo carácter representativo como instrumento idóneo de propaganda real y marcaban los límites del espacio específico del rey en relación con el de sus súbditos. En cambio, las literas se solían destinar para el uso de las damas y de los niños, y los trineos servían para paseos, excursiones, juegos y mascaradas $^{45}$.

El intento de frenar el progresivo lujo y abuso en la utilización de estos vehículos dio lugar a sucesivas pragmáticas reales que trataron de restringir su uso exclusivo a la nobleza y a los cortesanos a partir de $1611^{46}$. No se conserva ningún carruaje de esta época ${ }^{47}$, pero podemos hacernos idea de su aspecto a través de algunas pinturas flamencas como la de Isabel Clara Eugenia en el sitio de Breda, obra de Peeter Snayers (1626-1630), y El palacio real de Bruselas que pintaron Sebastian Vranex y Jan Brueghel el Joven (1625-1630) ${ }^{48}$. Respecto a la pintura española, recordamos la de Felipe IV cazando un jabalí (La tela Real) de la National Gallery de Londres que pintó

${ }^{45}$ El estudio más completo y actualizado sobre carruajes en la época de los Austrias desde el punto de vista de su funcionalidad y de su legislación es el de A. LOPEZ ÁLVAREZ, Poder, lujo y conflicto en la Corte de los Austrias. Coches, carrozas y sillas de mano, 1550-1700, Madrid, 2007.

${ }^{46}$ Entre 1578 y 1726 se promulgaron hasta seis pragmáticas para combatir los abusos, como recoge J. SEMPERE Y GUARINOS, Historia del luxo y de las leyes suntuarias en España, Madrid, 1788, Vol. II, pp. 53 y siguientes.

${ }^{47}$ Según E. GALÁN DOMINGO, “De las Reales Caballerizas a la colección de carruajes del Patrimonio Nacional", Arbor, no 665, 2001, p. 227, sólo ha sobrevivido la carroza de fabricación española en que Felipe III visitó Portugal en 1619. Se conserva en el Museu Nacional dos Coches de Lisboa.

${ }^{48}$ Véase, por ejemplo, A. VERGARA, "El palacio real de Bruselas", en ÍDEM (com.), El arte en la corte de los archiduques..., pp. 182-183. 
Velázquez (c.1636-38) con varias carrozas en primer término ${ }^{49}$.

En cuanto a los caballos españoles, García García comenta sus ricos aderezos haciendo hincapié en su valor material y en su carácter suntuario y ostentativo, ya que, en su opinión, "constituían los bienes de lujo, premio y ostentación más preciados de la Corona". Por estas razones, su saca estaba especialmente vigilada, salvo para los miembros de la familia real, para individuos estrechamente vinculados a la realeza o para el servicio específico del ejército y de los militares. Como ejemplos menciona los ocho caballos de su caballeriza que Felipe III envió a su tío el emperador Matías en el año 1612 como presente por su reciente proclamación; la jaca y los seis caballos que el duque de Lerma mandó a la infanta Isabel Clara Eugenia o un lujoso juego de guarniciones, aderezos y armas destinado al archiduque Alberto ${ }^{50}$.

Por nuestra parte, dejando a un lado todos aquellos documentos que no se refieren a regalos propiamente dichos $^{51}$, estimamos que el caballo era portador de un significado mucho más complejo. Un repaso a la historia del arte y a la literatura emblemática nos recuerda que a su belleza formal se podía añadir un profundo contenido simbólico en determinadas circunstancias, sobre todo cuando se trataba de obsequiar a determinados personajes. Respecto a lo primero, baste recordar el interés que su anatomía y su noble porte suscitaron entre grandes artistas del Renacimiento como Donatello,

\footnotetext{
${ }^{49}$ Reproducida, por ejemplo, en J. BROWN, Velázquez. Pintor y cortesano, Madrid, 1992, p. 130.

${ }^{50}$ B. J. GARCÍA GARCÍA, Op. cit., pp. 229-230.

${ }^{51}$ Entre los numerosos casos que podrían citarse sobre la saca de caballos para uso militar o para personajes importantes de la nobleza recogemos el del marqués de Camarasa, gentilhombre de cámara de Felipe IV y mayordomo mayor de su hermano el Cardenal Infante, que obtuvo licencia para llevar a los oficiales de Fuenterrabía diez caballos españoles a finales de julio de 1629, según documento del AHN, Consejos, Libro de Paso 636, fol.30r.
}

Verrocchio o Leonardo da Vinci. También en algunos lienzos de la primera mitad del siglo XVII se reproducen estos nobles brutos como protagonistas de la pintura. Es el caso del Caballo español del archiduque Alberto capturado en la batalla de Niewpoort, obra de Jacques de Gheyn II, del Rijksmuseum de Amsterdam $^{52}$ o el Caballo a la corbeta del Palacio Real de Madrid pintado por Velázquez en torno a $1634-37^{53}$.

En cuanto a su significado emblemático, Alciato lo propone como imagen del que no sabe lisonjear ${ }^{54}$. El emblema $n^{0} 64$ de Sebastián de Covarrubias que representa a un joven noble sobre un brioso corcel acompañado de la leyenda "Parce puer stimulis", es decir, "sé parco en el uso de la aguijada", se refiere a la formación del príncipe y nos enseña, según Hernández Miñano, que ambos -hombre y animal- se han de frenar en su juventud, mediante la razón y la educación el primero, y con mano dura el segundo $^{55}$. Significado análogo se desprende del emblema XCVII de Juan de Solórzano que lleva por mote "Vulgi latrati spernendi" y reproduce a un caballo en veloz carrera ${ }^{56}$. Parecidos consejos se recogen años después en la obra de $\mathrm{Mendo}^{57}$. Es decir, a lo largo del

${ }^{52}$ Reproducido por M. A. ECHEVERRÍA GACIGALUPE, “Los archiduques y su tiempo (1599-1633), en A. VERGARA (com.), El arte en la corte de los archiduques..., p. 36.

${ }^{53}$ J. LÓPEZ REY, Op. cit., no 67. Figura ya en el Inventario del Alcázar de Madrid de 1637.

${ }^{54}$ S. SEBASTIÁN, Op. cit., p.69, emblema XXXV.

${ }^{55}$ J. D. HERNÁNDEZ MIÑANO, "Sebastián de Covarrubias en sus emblemas morales", en Actas del I Simposio Internacional de Literatura emblemática hispánica, La Coruña, 1996, pp. 516-517. A. RUIZ DE ELVIRA, Emblemas morales de Sebastián de Covarrubias, centuria I, emblema 64, Murcia, 2015, pp. 165-168, recoge el parecer de Ovidio y se cuestiona si el freno y la vara son buenos métodos para someter a un caballo o reprimir los deseos del hombre en aras de una educación provechosa.

${ }^{56}$ J. de SOLÓRZANO, Emblemas regio políticos, Madrid, 1653, emblema no XCVII.

${ }^{57}$ A. MENDO, Príncipe perfecto y ministros ajustados, documentos políticos y morales, Salamanca 1657, p. 18. Como muestra de la distinta valoración de la obra de 
siglo XVII, la literatura emblemática consideraba que el caballo ejem-plificaba la imagen del buen gobernante y lo asociaba con la fortaleza y con el espíritu del príncipe que había de mantenerse fiel a sus ideas políticas sin admitir adulaciones que intentasen desviarlo de su verdadero camino ${ }^{58}$. Por lo tanto, la equitación tenía que formar parte fundamental de su educación, porque el dominio del jinete sobre el caballo era reflejo del poder que el futuro soberano tenía que ejercer sobre sus súbditos, es decir, constituía una imagen visible del buen gobierno ${ }^{59}$.

En consecuencia, de acuerdo con la alta estima que merecían estos nobles animales y con el rango que habían de tener los destinatarios de tales regalos, pero también de acuerdo con la literatura emblemática de la época, consideramos que el príncipe Baltasar Carlos, hijo de Felipe IV y futuro rey de España, era uno de los receptores más idóneos para este tipo de presentes $y$, de acuerdo con el citado documento del año 1634, fue obsequiado con una jaca que su tío, el cardenal infante don Fernando, le remitió en el transcurso de la jornada de Flandes. Seis caballos junto con una carroza y todas sus guarniciones le había regalado el año anterior el príncipe de Venosa ${ }^{60}$, al tiempo que el conde de Monterrey, a la sazón virrey de Nápoles, le enviaba desde el virreinato un coche y una litera con todos sus aderezos ${ }^{61}$.

Solórzano en la bibliografía reciente, contraponemos los pareceres de B. ANTÓN MARTÍNEZ y C. HEESAKKERS, “Herederos de Alciato en Holanda y España: Adriano Junio (Emblemata) y Juan de Solórzano (Emblemata Centum Regio Politica)", Minerva: Revista de Filología Clásica, nº 16, 2002-2003, pp. 131-172, y la introducción de A. M. REY SIERRA a la edición facsímil de A. MENDO, Príncipe perfecto y ministros ajustados, Lyon, 1662.

${ }^{58}$ J. M. GONZÁLEZ DE ZÁRATE, Emblemas regio políticos de Juan de Solórzano, Madrid, 1987, p. 100.

${ }^{59}$ J. GÁLLEGO, Visión y símbolos de la pintura española del Siglo de Oro, Madrid, 1978, pp. 272-275.

${ }^{60} \mathrm{AHN}$, Consejos, Libro de Paso 635, fol. 276v.

${ }^{61}$ B. J. GARCÍA GARCÍA, Op. cit., p. 232. Según A. LÓPEZ ÁLVAREZ, Op. cit., pp. 59 y 121, la litera era una caja decorada con textiles y sustentada en dos varales
Por estas fechas el príncipe estaría iniciando su formación como futuro gobernante. Por lo tanto, habría que considerar el significado último de estos presentes a la luz de la emblemática. Incluso cabría pensar que la jaca enviada por el cardenal infante fuese la misma que le sirve de pedestal regio en el retrato ecuestre del Salón de Reinos, hoy en el museo del Prado, pintado por Velázquez entre 1633-1635 a partir de uno de los grabados de Tempesta sobre las Vidas de los doce Césares. Palomino comentaría más tarde sobre este cuadro que "aunque de pocos años, armado y a caballo, con el bastón de generalísimo en la mano, en una jaca; la cual corriendo con gran ímpetu y veloz movimiento, parece que con impaciente orgullo, respirando fuego, solicita ansiosa la batalla, prevista ya en su dueño la victoria" ${ }^{62}$. Jinete sobre un caballo a la corveta en un difícil ejercicio de doma se representa también en La lección de equitación del príncipe Baltasar Carlos de la colección del duque de Westminster, pintura tradicionalmente atribuida a Velázquez y considerada hoy posible obra de Alonso Cano, pintor de cámara del conde duque de Olivares $^{63}$. En este caso el caballo se ha considerado un regalo del valido al príncipe, tras la orden que le dio Felipe IV para que fomentase la cría de estos animales en Andalucía $^{64}$.

También es posible que se refiera al propio Baltasar Carlos el manual de Saavedra Fajardo Idea de un príncipe político cristiano, editado en 1640. Al menos la empresa no ${ }^{\circ} 38$,

que transportaban caballerías, y se utilizaba sobre todo para el transporte de las damas. Pero recoge también el relato del padre Flores sobre el bautizo de Baltasar Carlos en que el pequeño infante fue transportado en una silla de cristal.

${ }^{62}$ J. GÁLLEGO, Op. cit., pp. 272-274. La frase entrecomillada está recogida literalmente de A. A. PALOMINO, El Museo Pictórico y Escala Óptica, Madrid, 1715, p. 907 (edición de Madrid, 1947, con prólogo de Juan Agustín Ceán Bermúdez).

${ }^{63}$ M. del M. DOVAL TRUEVA, "Alonso Cano y los retratos del príncipe Baltasar Carlos", Goya, no 232, 2010, pp. 206-207.

${ }^{64} \mathrm{Ibídem.}$ 
que reproduce a un joven sobre un caballo a la corveta con el mote "con halago y con rigor", identifica al jinete con el ideal político de todo príncipe, ya que "Menester es el freno de la razón, las riendas de la política, la vara de la justicia y la espuela del valor, fijo siempre el príncipe en los estribos de la prudencia" $^{65}$.

Paralelamente, entre 1627 y 1631, Felipe IV intercambiaba enseres variados con otros parientes o con miembros de la realeza europea, entre ellos su hermana la reina Ana de Francia ( 4 baúles y un escritorio), el príncipe de Polonia (unos martinetes) ${ }^{66}$ o la reina de Hungría (agua de ámbar) ${ }^{67}$. Pero las piezas más valiosas parecen las "tres guarniciones para cavallos hechos de piedra de Bohemia engastados en plata y una silla de lo mismo" que le mandó el rey de Hungría en 1628 con el conde de Franqueburg ${ }^{68}$. Estas guarniciones y sillas de montar de plata no eran productos exclusivos de los países centroeuropeos. En España se confeccionaron al menos desde el siglo XVI, según atestiguan numerosos inventarios y contratos de obras, si bien todas ellas han desaparecido. Citamos como ejemplo la silla de montar que el platero Antonio de Arfe labró para la VI condesa de Benavente ${ }^{69}$.

En cuanto al papel de los embajadores destinados en Italia, su misión principal consistió en actuar como agentes artísticos del monarca español, pero no podemos descartar que algunos encargos acabasen subvencionados por ellos mismos. En cu-

${ }^{65}$ D. SAAVEDRA FAJARDO, Idea de un príncipe político cristiano, Milán 1642, empresa $\mathrm{n}^{\circ} 38$ que lleva por título "Con halago y con rigor".

${ }^{66}$ Según el Diccionario de la $R A E$, el martinete es un penacho de plumas de la garza gris.

${ }^{67} \mathrm{AHN}$, Consejos, Libro de Paso 635, fol. 363r. y Libro de Paso 636, s/fol.

${ }^{68}$ Ibídem, fols. 493v.-495r.

${ }^{69}$ B. SANTAMARINA, "Obra documentada de Antonio de Arfe para el VI Conde de Benavente. Estudio de tipos de platería civil en el siglo $\mathrm{XVI}^{\prime \prime}$, Anuario del Departamento de Historia y Teoría del Arte (U.A.M.), VI, 1994, pp. 197-204. alquier caso, el marqués de Castel Rodrigo, embajador ante la Santa Sede, mandó a Madrid "7 cajas que tienen cerca de siete palmos cada una de largo cubiertas de angeo y selladas con sus armas en las cuales vienen algunas pinturas para adorno del Buen Retiro", en $1639^{70}$. El documento se refiere a los lienzos de Claudio de Lorena que actualmente se guardan en el Museo del Prado ${ }^{71}$. Según Juan José Luna, Felipe IV había solicitado ocho pinturas de este autor; cuatro de anacoretas, de formato horizontal, de las que se conservan tres (San Antonio Abad, La Magdalena penitente y Un paisaje con un anacoreta) y otros cuatro de asuntos diversos y de formato vertical (Moisés salvado de las aguas, Entierro de santa Serapia, Embarco en Ostia de santa Paula Romana y El arcángel Rafael y Tobías) ${ }^{72}$.

Al año siguiente el marqués de Leganés, gobernador de Milán, remitió un amplio y complejo conjunto de frontales y ornamentos litúrgicos; una cama de nogal con todos sus aderezos de plata y bordados, incluido un orinal de plata, un doselillo con reliquias de san Carlos Borromeo, un par de banquetas de campaña y una silleta para el prínci$\mathrm{pe}^{73}$. No obstante, el regalo más singular fue la góndola y las dos falúas que llegaron en la Navidad de 1627 de parte del duque de Alba y virrey de Nápoles, don Antonio Álvarez de Toledo $^{74}$, y que, dada la fecha, estarían destinadas al esparcimiento de los monarcas en la ribera del Tajo en el Real Sitio de Aranjuez, puesto que el complejo del Buen Retiro aún no se había iniciado.

${ }^{70}$ Recogido por B. J. GA2RCÍA GARCÍA, Op. cit., p. 235.

${ }^{71}$ P. VARELA GOMES, "Damnatio memoriae. A arquitectura dos marqueses de Castelo Rodrigo", en J. L. COLOMER, (dir.), Op. cit., pp. 351-378. Recoge los estudios de Wittkower, Pérez Sánchez y Elliot sobre los contactos del marqués con los artistas italianos.

${ }^{72}$ J. J. LUNA, "Precisiones sobre las pinturas de Claudio de Lorena en el Museo del Prado", Boletín del Museo del Prado, no 85, 1981, pp. 99-110.

${ }^{73} \mathrm{AHN}$, Consejos, Libro de Paso 636, fol. 521r.

${ }^{74}$ B. J. GARCÍA GARCÍA, Op. cit., p. 240. 
En el caso de los indianos, las "donaciones graciosas" a Su Majestad Católica destacaban con frecuencia por su carácter espectacular o por su riqueza extraordinaria. No hay más que recordar el papagayo de oro, plata y piedras preciosas que llegó para el rey de parte del Marqués de Cerralbo, virrey de México, y que, de acuerdo con las declaraciones del dominico irlandés Thomas Gage, estaba valorado en 6.000.000 de reales, es decir, unos 545.454 ducados $^{75}$. De su aspecto podemos hacernos una ligera idea a través del diseño del joyel de Guadalupe o del pinjante del Museo Arqueológico Nacional, si bien el papagayo del virrey debía ser de mayor tamaño y riqueza a juzgar por su alto precio $^{76}$.

A semejanza del monarca, también su primera esposa, Isabel de Borbón, estuvo fuertemente implicada en esta problemática de los regalos a través de los cuales mantuvo frecuentes contactos con sus familiares más allegados, sobre todo con su madre, la reina Ana de Francia. En los Libros de Paso se documentan una decena de ocasiones en que ambas soberanas intercambiaron presentes entre los años 1623 y 1634, aunque su contenido no siempre se declara. Por ejemplo, en 1627 Isabel envió a la corte de París "tres caxuelas cubiertas de encerado verde"77. Entre los obsequios que sí se detallan predominan los cordobanes y los guantes de ámbar o de jazmín, bandas y agua de olor, bolsos, pas-

${ }^{75}$ Recogido en C. HEREDIA MORENO, "Trayectoria del virrey de México don Rodrigo Pacheco y Osorio y de su patrimonio suntuario al servicio de Felipe IV", en Aurea Quersoneso. Estudios sobre la plata iberoamericana. Siglos XVI-XIX, México, 2014, pp. 125-140. Regalo no menos extraordinario recibiría su sucesor Carlos II en la flota de Tierra Firme del año 1697 de parte de don Juan Francisco de Páramo y Cepeda, caballero de San Jorge y presbítero del obispado de Tierra Firme. En este caso se trataba de una caja de plata que contenía una cajetilla de oro esmaltado con una perla de 55 quilates (Vid. ÍDEM, "Viajes transatlánticos. Objetos artísticos en las flotas de Tierra Firme durante el reinado de Carlos II", en El arte y el viaje, Madrid, 2011, p. 538.

${ }^{76}$ Ambos los reproduce P. MULLER, Jewels in Spain, New York, 1972, lám. 4 y fig. 147.

${ }^{77}$ AHN, Consejos, Libro de Paso 635, fol. 377r. tillas, piedras bezares, rosarios y todo tipo de menudencias como búcaros, porcelanas, cajas bordadas, brincos, etc. ${ }^{78}$. Uno de los lotes más interesantes fue enviado a París en junio de 1623 e incluía una silla, un escritorio y un bufete de concha de tortuga, una caja con cosas de olor y de la India y un baúl con cajas con cordobanes de jazmín, agua de olor y manteca de azahar ${ }^{79}$. Piezas interesantes parecen también el par de biombos grandes que la reina Ana de Francia recibió de su hija en el año 1630 y que responden al gusto por lo exótico tan generalizado en la época ${ }^{80}$.

Con parecida frecuencia, la reina Isabel envió o intercambió recuerdos con otros familiares a partir de 1624. En esta fecha mandó a Isabel Clara Eugenia un baúl y un escritorio bordados de oro sobre cuero de ámbar con treinta cordobanes y faltriqueras de ámbar, pastillas, flores y pebetes, al tiempo que la infanta Margarita recibía de su parte una escribanía de ébano ${ }^{81}$. Cinco años más tarde, el pintor Pedro Pablo Rubens, de regreso a su patria tras su segunda estancia en la corte de Madrid, llevaba a Flandes ciertos encargos de parte de la reina de España: "Sabed que la serenisima reina, mi muy clara y muy amada mujer, enbia con Pedro Pablo Rubens a la señora infanta, mi tia, un rosario de calambuco tachonado de diamantes y oro que va en una caxa larga cubierta de encerado verde y veinte y dos pares de guantes de ámbar. Por ende os mandamos se los dexeis y consintais pasar por cualquiera de esos puertos sin abrir, ni escudriñar, pedir ni llevar derechos ni otra cosa alguna..." ${ }^{82}$.

${ }^{78}$ Vid. por ejemplo, Ibídem, fol.350v. M. P. AGUILÓ ALONSO, "Cordobanes y guadamaciles", en A. BARTOLOMÉ ARRÁIZA (coord.), Las artes decorativas en España, T. II, Madrid, 1999, p. 275, nos recuerda que los cordobanes se solían perfumar en el siglo XVII con ámbar, esencia de jazmín, rosa u otras sustancias aromáticas, igual que los guantes de cuero y que ambos productos eran muy apreciados como regalos.

\footnotetext{
${ }^{79} \mathrm{AHN}$, Consejos, Libro de Paso 635, fol. 59r. y 59v.

${ }^{80}$ Ibídem, Libro de Paso 636, fol. 89r.

${ }^{81}$ Ibídem, Libro de Paso 635, fols. 143v.-144r.

82 Ibídem, Libro de Paso 636, s/fol.
} 
Tanto en esta como en otras muchas ocasiones, es posible que, al menos, parte de las alhajas que regalaban los reyes se hubieran hecho en el entorno de la corte por mano de los plateros reales o que, al menos, fuesen de factura madrileña. A este respecto, cabe apuntar los nombres de Diego de Zabalza, platero de la reina Isabel de Borbón entre 1618 y 1636; su hijo Luis, platero de la reina a partir de 1636 y del rey desde 1642 ó Juan de Huete, platero del rey desde 1612 hasta el 1641, sin descartar a otros artífice de prestigio $^{83}$.

Intensos fueron también los contactos de Isabel de Borbón con su cuñada la reina de Hungría a la que obsequió repetidas veces con enseres de todo tipo, desde productos comestibles hasta cajas y escritorios repletos de guantes y cosas de ámbar, menudencias, prendas de vestir y alhajas diversas. Entre estas últimas se cuentan un relicario de diamantes pendiente de una cadena de oro, un cuadro de la India guarnecido de plata y una gargantilla, ajorcas y arracadas de oro esmaltadas de girasoles ${ }^{84}$. El último envío tuvo lugar en 1637 e incluía cinco cajas cubiertas de encerado, dos con joyas, salvas y otras cosas de plata, otras dos cajas con chocolate y la última con unas conservas ${ }^{85}$. Por su parte, la de Hungría agradeció estos obsequios en 1631con ricos presentes para la familia real española, a saber, un escritorio de ébano y plata con una botica de plata de 17 piezas, una escribanía con todo recado de valor de 300 ducados, una rosa de diamantes esmaltada de blanco para el rey valorada en 300 ducados, 3 rosas más pequeñas de diamantes esmaltadas de blanco para la reina, de valor de 4000 reales, y una pluma de dia-

\footnotetext{
${ }^{83}$ J. M. CRUZ VALDOVINOS, "Platería", en A. BARTOLOMÉ ARRÁIZA (coord.), Op. cit., pp. 589-

${ }^{84}$ AHN, Consejos, Libro de Paso 636, fols. 269v., 313r., 323v., 363v. y 381r.

${ }^{85}$ Ibídem, fol. 430r. De parecida índole, salvo un escritorio de plata, fueron los regalos intercambiados entre la reina de Hungría y la de Francia entre 1626 y
} 91. 1633. mantes pequeña para el serenísimo infante don Carlos, que se estimó en 390 reales $^{86}$.

En cuanto a los regalos que la reina Isabel recibió durante estos mismos años, el más extraordinario fue un completo ajuar para amueblar y acondicionar un dormitorio infantil que le remitió en febrero de 1624 la emperatriz Leonor Gonzaga, segunda esposa de Fernando de Austria, para su parto ${ }^{87}$. Sin duda debe referirse al nacimiento de Margarita María Catalina, que tuvo lugar en noviembre de 1623, pero, desgraciadamente, cuando el cargamento llegó a España, la infantita ya había fallecido. El mismo carácter de felicitación por su reciente maternidad tendrían las siete cajas con una cama de madera guarnecida con todos sus aderezos de telas de oro, dosel y brocados con colgaduras que le mandó desde Florencia el gran duque de Toscana a través de su embajador en la corte de Madrid en marzo de $1624^{88}$.

De manera excepcional se documenta también que Isabel de Borbón mandó a la reina de Inglaterra un escritorio y un baúl de la India, un par de frasqueras con juncos de plata y una caja con pastillas y pebetes en el año $1638^{89}$. Dos años después, la archiduquesa Claudia enviaba a la serenísima reina de España un curioso y variopinto conjunto de enseres: "[...]una caja con el sobre escrito "a la serenísima reina" con algunas flores de seda entrelazadas de oro y plata y otra caja con el mismo sobrescrito con un reloj grande con varias invenciones, otro en forma de cruz, otros cuatro

${ }^{86}$ Ibídem, fol. 173r. Estos tipos de alhajas eran bastante comunes en el siglo XVII como complemento de los atuendos personales. En concreto, la pluma de diamantes se utilizaba como adorno de los sombreros masculinos. Los documentos no permiten identificarlos, aunque sí podemos apreciar su aspecto y su riqueza a través de las piezas conservadas y de los retratos cortesanos de la época de Felipe IV pintados por Velázquez y otros maestros. Vid. L. ARBETETA MIRA, "Joyería”, en B. ARRÁIZA (coord.), Op. cit., pp. 187-218.

\footnotetext{
${ }^{87}$ B. J. GARCÍA GARCÍA, Op. cit., pp. 246-249.

${ }^{88}$ AHN, Consejos, Libro de paso 635, fol. 116v.

${ }^{89} \mathrm{Ib}$ ídem, Libro de paso 636, fol. 457v.
} 
pequeños, una cajeta con un aparador de plata para muñecas, un baulito de marfil donde hay dos relojitos un estuche y otras menudencias, una cajita de galanterías de ámbar amarillo y dos galanes de oro con perlas, seis docenas de guantes, un cuadro de marfil y otros diferentes con otros dos pequeños de cera, una vitela y otras imágenes, seis envoltorios para algunas damas de la serenísima reina, un pomito de plata para aguas de olor, dos pistolas con sus aderezos de la misma labor, unos alamares de acero, una cuchilla de monte con un par de espuelas, y en la tercera caja un tocador de plata y algunas menudencias. Madrid, 15 de mayo de $1640^{\prime \prime 90}$.

El aparador y los baulitos parecen juguetes para uso infantil que podrían estar destinados a la infanta $\mathrm{M}^{\mathrm{a}}$ Teresa. No obstante, sus materiales permiten apuntar también que se tratase de objetos de adorno para engalanar las habitaciones de la reina.

De la misma manera, jugaron un papel significativo las relaciones e intercambios de obsequios de las infantas Isabel Clara Eugenia y Margarita, entre sí o con otros miembros de la realeza europea. Margarita (†1633) había llegado a Madrid en el año 1581 con su madre María de Austria, la emperatriz viuda de Maximiliano II, y ambas habían ingresado en el monasterio de las Descalzas fundado por la esposa de Felipe III. Los estrechos vínculos de Isabel con su prima Margarita y con el monasterio madrileño se tradujeron en la práctica en el conocido y valioso conjunto de veinte tapices sobre El Triunfo de la Eucaristía, confeccionados en Bruselas entre 1625-1628 en los telares dirigidos por los maestros Jan Roes II, Jan Vervoert y Jacques Fobert a partir de cartones de Rubens ${ }^{91}$. Según los documentos dados a conocer por Ana García Sanz, los tapices llegaron a Madrid en diferentes lotes entre los años 1628 y 1633 y se utilizaron en festividades impor-

\footnotetext{
${ }^{90}$ Ibídem, fol. 521v.

${ }^{91}$ C. HERRERO CARRETERO, "Tapices", en A. BARTOLOMÉ ARRÁIZA, Op. cit., pp. 192-193.
}

tantes como el Viernes Santo y la Octava del Corpus Christi ${ }^{92}$.

Carácter religioso para servicio del culto tienen otros muchos de los presentes que intercambiaron Margarita e Isabel Clara Eugenia entre 1632-1633, aunque entre ellos se intercalan también menudencias y retratos. De esta forma, Isabel mandó desde Flandes para el monasterio de las Descalzas de Madrid un tabernáculo de madera dorada con fondo blanco, articulado por cuatro columnas y unos arcos de remate, un retrato de su alteza, diversos ramilleteros para poner flores en los altares, cuatro tapices pequeños, cenefas para casullas, frontaleras con sus caídas para el altar mayor y colaterales más otra para la grada del altar mayor bordada de oro y perlas ${ }^{93}$.

En respuesta y para satisfacer sus deseos, Margarita le mandó algunas esculturas para su oratorio, rosarios y libros de devoción y un variopinto conjunto de objetos exóticos procedentes de la India o de las Indias Occidentales, menudencias y dulces, a saber: "La señora infanta doña Margarita, mi tia, envia a Flandes a la señora Infanta doña Isabel, mi tia, algunas cosas de oratorio juntamente con otras que su alteza ha enviado a pedir y todo va en 4 cajones. En la del $\mathrm{Nu}$ mero primero doce serafines de escultura, 6 ángeles della, un Niño Jesús y un san Juan. En el numero 2 seis ollas de miel rosada de azucar. En la del número tercero seis ollas de miel de la Puebla, en la del numero cuarto van 5 caxas que en la una va una canastilla de Portugal y dentro tres cestillas de paxa, una con cruces de Santo Toribio, otras con cruces de tortuga y otra de florecillas, seis caxillas de tortuga con unos rosarios de lo mismo y pastillas de olor, dos rosarios de coco, seis rosarios de mensur, en otra caxa

92 A. GARCÍA SANZ, "Nuevas aproximaciones a la serie el Triunfo de la Eucaristía", en A. VERGARA (com.), El arte en la corte de los archiduques..., pp. 108-117. La autora trata también de reconstruir la colocación de la tapicería con motivo de las fiestas.

${ }^{93} \mathrm{AHN}$, Consejos, Libro de paso 636, fols. 221v. y 259 r. 
de las que van dentro desta seis cajitas de acero con pastillas, dos bordaduras de paxa, unos rosarios de bucaro y barritos, una toga de confeccion de olor, otra caxa de las que van dentro de las del numero cuarto va llena de flores, en otra va una bordada de ámbar y dentro un rosario de palo de águila engarzado en plata dorada con una imagen de lo mismo, otras caxas bordadas con rosarios de varro dentro, una Arquita bordada de ámbar llena de vasitos dorados, una aguadera de ambar con vasitos dorados, dos faltriqueras de ámbar, dos bandejitas de talco doradas y pintadas, otra bandejita de la Yndia, dos acericos bordados, dos cruces una de santo Toribio y otra de tortuga, 4 porcelanas chicas que son dos escudillas y dos platillos, doce barros medianos y otra media docena pequeños dorados, 4 rosarios de barro dorados y dos colorados. En otra de las dichas cinco cajas va dos cofrecillos de cuero de ámbar, dos rosarios de palo de águila, 4 pares de guantes de ámbar, dos pares de medias de seda de olor, 4 bolsos de ambar bordados, una arquilla bordada de ambar con pastillas de olor, dos libros de sermones. Osera, 25 de mayo de $1632^{\prime \prime 94}$.

A su vez, la infanta Margarita mantuvo contactos con los emperadores, infantes y demás familiares a los que obsequió en varias ocasiones con cordobanes, guantes, abanicos, bolsillos y cajas de cuero adobados de ámbar, cintas de tocas, bandas, apretadores, colchas de seda, paño fino, cofias de red de oro, un mazo de hilo de pita, piedras bezares, copas de pasta, libros de devoción, pastillas, pebetes y rosarios de $\operatorname{coco}^{95}$.

Del mismo tipo eran los regalos que Margarita había remitido a la princesa Isabel de Módena, a sus sobrinas las infantas de Saboya en 1629 o a las duquesas de Módena y de Toscana en $1631^{96}$. Entremezclados

\footnotetext{
${ }^{94}$ Ibídem, fols. 223r. y siguientes.

${ }^{95}$ Ibídem, Libro de paso 635, fols. 41v.-42v., 133v. y $391 r$.

${ }^{96}$ Ibídem, fols. 19v.-20r. y 178v. Libro de paso 636, fols. 31r., 193r. y 196r.
}

con todas estas menudencias, se recogen un bulto de Santa Margarita, un "bufetico" de cordobán y un par de retratos pintados en lienzo para la princesa Isabel. Por último, poco antes de su muerte ordenó que se remitiesen a sus sobrinas las infantas de Saboya dos Niños Jesús, 18 libros de devoción y algunas piedras bezares y cruces ${ }^{97}$.

Más allá del ámbito familiar o doméstico y más directamente vinculados al terreno de la diplomacia se sitúan los presentes que Felipe IV ofrecía a los embajadores, nuncios y representantes de las cortes europeas al concluir sus servicios. Según Malcolm, cada diplomático recibía una joya como regalo del soberano anfitrión al terminar su estancia en Madrid $^{98}$. No obstante, si bien las alhajas eran los obsequios más repetidos, también se prodigaban otro tipo de dádivas, lo que nos induce a pensar que el rey tenía en cuenta en cada caso la categoría del destinatario, la calidad del servicio prestado y la función de propaganda de la monarquía española que el obsequio tenía que desempeñar en el lugar de destino, como signo explícito de su poder y majestad ${ }^{99}$. De ahí que, dependiendo de las circunstancias, los Libros de Paso incluyan caballos, sillas de montar, armas, cadenas y joyas de oro -de adorno o de carácter devocional-, todo tipo de prendas suntuarias, retratos y medallas de los soberanos y de sus hijos, e, incluso, animales exóticos. Casi siempre se detalla el tipo de objetos y, en el caso de las alhajas, sus materiales y su precio, como testimonio fehaciente de la generosidad del soberano.

Entre estos documentos se encuentra el de los embajadores grisones de los cantones suizos católicos en el año 1639, dado

${ }^{97}$ Ibídem, Libro de paso 636, fol. 291r.

${ }^{98}$ A. MALCOLM, Op. cit., p. 161.

${ }^{99}$ M. C. de CARLOS, Op. cit., en B. ALONSO, M. C. de CARLOS y F. PEREDA, Op. cit., pp. 216-217, cita las categorías para regalar que se tuvieron en cuenta en la embajada de Inglaterra de 1604 según se recoge en la correspondencia entre el VI Condestable de Castilla y el conde de Villamediana. 
a conocer por García García ${ }^{100}$. Tras su participación en una embajada extraordinaria en la corte española, se les dio licencia para llevar a su tierra un abultado equipaje con productos de los territorios hispanos, joyas y objetos devocionales donados por el rey $\mathrm{o}$ adquiridos en la corte. Entre los posibles regalos destacan "16 cadenas de oro de diferentes hechuras y de valor de 48.538 reales" y "20 retratos míos, del príncipe y del conde duque de Sanlúcar", además de cruces de Caravaca, conchas de tortuga, libros de devoción y un largo etc.

Pero pueden citarse otros muchos casos interesantes. Por ejemplo, el embajador de Polonia llevaba consigo en el año 1623 "una joya que le dimos aovada a modo de una flor con 173 diamantes entre grandes y pequeños de valor de 6000 ducados poco mas o menos" ${ }^{\prime 101}$. En 1626, el cardenal Barberini obtuvo licencia para trasladar a Italia 4 caballos españoles con sus jaeces, frenos y aderezos, 6 sillas con sus aderezos y un equipaje con 72 cajas repletas de cosas de la India, libros, rosarios, cocos, guantes, borceguíes y pieles de ámbar, reposteros, colgaduras, juegos de pontifical, etc. ${ }^{102}$. Al mismo tiempo, los caballeros de su séquito recibieron del monarca español 35 cadenas y medallas y algunos cintillos de oro y diamantes ${ }^{103}$.

El marqués de Ruol, embajador del duque de Módena, volvió a Italia con paños de Segovia y con diversas cosas de la India, pero también llevaba por orden expresa del rey 24 cadenas de oro de 100 escudos cada una, 50 medallas de oro "de mi retrato" y un par de joyas de oro y diamantes que se estimaron en 3000 ducados $^{104}$. Al año siguiente el soberano hizo merced de otra cadena de oro a Diego Colart, capitán de un galeón en Dun-

${ }^{100}$ Documento dado a conocer por B. J. GARCIA GARCÍA, Op. cit., pp. 241-242.

\footnotetext{
${ }^{101}$ AHN, Consejos, Libro de paso 635, fol. 88r.-88v.

${ }^{102}$ Ibídem, fol. 319r.

${ }^{103} \mathrm{Ibídem}$, fol. 327v.

${ }^{104}$ Ibídem, fols. 291v. y 294v.
}

querque, "por lo bien que nos ha servido"105. Al general don Fernando Ribero, caballero de la orden de Santiago, le hizo merced de darle de "nuestra caballería" una litera con sus machos y 2000 ducados de ayuda de costas para llevar a Flandes ${ }^{106}$. Domingo de Estrada, secretario de la embajada de Flandes, marchó a su tierra con un retrato del príncipe, dos sortijas de diamantes y guantes de jazmín y de nácar, entre otras menudencias $^{107}$. El barón de Soucles, embajador del duque de Orleans fue agraciado en 1632 con una joya valorada en 1000 ducados ${ }^{108}$ y el capitán Francisco Martelli con otra alhaja que "le avemos hecho merced" que se estimó en 1500 escudos $^{109}$.

Por su parte, el embajador extraor-dinario de la cristianísima reina madre regresó a Flandes en 1634 con un par de retratos de la serenísima reina de España, otros dos del serenísimo príncipe, cordobanes "de todas flores", manteca de azahar, aceite de jazmín, redomas de agua de mosqueta, barriles de flor de azahar, de limas romanas y de diferentes confituras, cinco libras de chocolate y dos Niños Jesús de madera encarnada ${ }^{110}$. De la misma manera, en 1637 el conde de Salazar se llevó a su tierra 208 medallas con la efigie del rey ${ }^{111}$. Retratos de los reyes y del príncipe y una joya y cadena de oro llevaba consigo también el marqués Aníbal Gonzaga, embajador de la emperatriz, cuando se marchó en $1639^{112}$. No obstante, los obsequios más exóticos fueron los tres camellos que Su Majestad entregó al conde de Algmont, embajador de la infanta doña Isabel, cuando volvió a Flandes en el año $1626^{113}$.

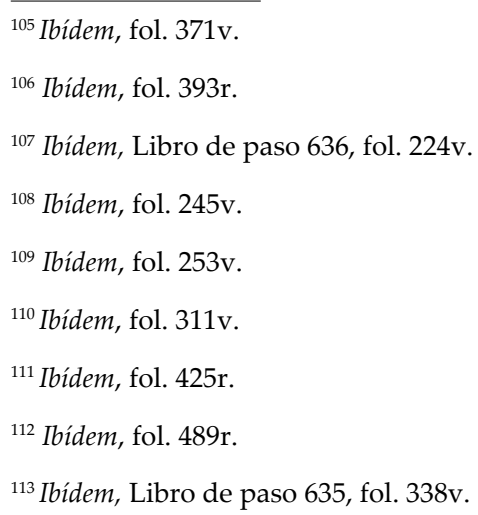


Los contactos diplomáticos con el ducado de Saboya también fueron frecuentes. En 1629 el abad de la Escala, embajador del duque, fue obsequiado por Felipe IV con "una joya de diamantes a manera de rosa con una flor de lis"114, mientras que el mayordomo de la duquesa recibía tres años después un retrato del serenísimo príncipe Baltasar Car$\operatorname{los}^{115}$ y el marqués Ludovico Forni, embajador extraordinario, regresaba a Italia en 1635 con piedras bezares, varios cofrecillos de tortuga guarnecidos de plata, una escribanía de la India y tres retratos del rey, la reina y el príncipe $^{116}$.

Es decir, según los datos que hemos manejado, en el transcurso de estas dos décadas -1621-1641- Felipe IV entregó un total de treinta y dos retratos de los reyes y del príncipe heredero más 208 medallas de oro con su efigie a los embajadores de Suiza, Polonia, Roma, Flandes, Saboya, Módena o Alemania. No obstante, pensamos que algunas pinturas no estarían destinadas a los propios embajadores, sino que éstos actuarían como intermediarios encargados de su transporte y entrega a parientes europeos de los monarcas españoles, sobre todo los de Flandes y Alemania. En tales casos, sin olvidar el sentido de propaganda y de manifestación de poder implícito en los retratos reales ${ }^{117}$, las pinturas cumplirían una función sustitutiva, como recuerdo familiar de los monarcas ausentes o como forma de conocer al príncipe heredero, quizás con vistas a su futuro enlace matrimonial ${ }^{118}$.

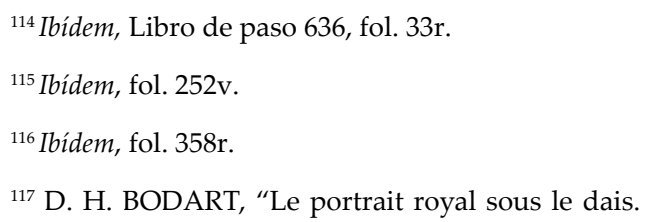
Polysèmie d'un dispositive de representation dans l'Espagne et dans Italie du XVIIe siècle", en J. L. COLOMER (dir.), Op. cit., pp. 89-111.

${ }^{118}$ Los modelos de estos retratos de la familia real hay que buscarlos en los realizados por Velázquez desde 1623 hasta comienzos de los años cuarenta, como el Felipe IV de pie, del Museo del Prado o Felipe IV en marrón y plata, y en las copias que de ellos realizaron los maestros de su entorno. Los reproducidos por J.
Un carácter propagandístico de difusión de la propia imagen y del poder y majestad del rey tendrían, en cambio, las medallas con la efigie del soberano. Es decir, difundir la figura del monarca español fuera de sus fronteras para proclamar su grandeza puede ser el motivo de que el marqués de Ruol llevase 50 medallas "de mi retrato" (de Felipe IV) a Módena o de que se entregaran al conde de Salazar otras 208 unidades al regresar a Saboya ${ }^{119}$. Estas medallas hay que insertarlas en la tradición de la Antigua Roma, renovada por Pisanello en el Quattrocento italiano. Se conocen varias obras del toscano Rutilio Gaci, platero y broncista, que sustituyó al florentino Gian Paolo Poggini como medallista "semi oficial" en la corte de Madrid en el año 1559 y que realizó la medalla de la coronación de Felipe IV en el año $1621^{120}$. Al mismo Gaci se debe la del Gabinete de Antigüedades de la Real Academia de Historia fundida en bronce antes de 1634, que lleva su monograma -RVTO- y que fue copiada por un desconocido broncista de su entorno -MA.SP.F.- ${ }^{121}$. De acuerdo con los modelos clásicos y renacentistas, el anverso reproduce el busto del rey, de perfil derecho, ataviado con coraza y gorguera, y rodeado de la inscripción PHILIPPVS IIII HISPANIARVM $R E X$. El reverso se ilustra con la cuadriga de Apolo con el globo del mundo y la leyenda ILVUSTRAT ET FOVET.

Estos ejemplos y algunos otros semejantes de la misma colección permiten suponer que las medallas oficiales, hechas por plateros o broncistas de la corte española, se

LÓPEZ REY, Op. cit., entre el nº 36 y el 90, pueden servirnos de ejemplo.

${ }^{119}$ Sobre las medallas de Felipe IV puede consultarse J. BABELON, “Felipe IV y el Conde Duque de Olivares en el arte de la medalla", Cuadernos Hispanoamericanos, no 140,1961 , pp. 177 y siguientes.

${ }^{120} \mathrm{M}$. GIMENO, "El arte de la medalla en España", en M. JONES, El arte de la medalla, Madrid, 1988, pp.319320.

${ }^{121}$ M. ALMAGRO-GORBEA, M. C. PÉREZ ALCORTA y T. MONEO, Medallas españolas, Madrid, 2005, pp. 87-89. 
repetían en serie o eran copiadas por otros artífices y que éste fue el modelo que se divulgó por Europa a través de los regalos del monarca, con variantes en los materiales -oro, plata o bronce-, en la vestimenta del efigiado y en la temática del reverso ${ }^{122}$.

En el ámbito de los virreyes de Nápoles también consta esta costumbre y sabemos, por ejemplo, que el medallista Giulio de Grazia, amigo de José de Ribera, realizó un par de medallas con el retrato del duque de Alba, una de ellas fechada en $1623^{123}$.

En suma, las licencias de los Libros de Paso recogen un sinfín de pinturas, esculturas, objetos suntuarios, alhajas y joyas de todo tipo que muestran los gustos, aficiones y devociones de la realeza y de las capas altas de la sociedad de la época. También in- forman sobre las múltiples funciones que podían cumplir los regalos en el entorno de las cortes y de la diplomacia contemporánea, tanto como objetos de coleccionismo, como expresión de alianzas y lealtades o como premio por los servicios prestados, cuanto como materialización de afecto y de cariño en el ámbito familiar. Pero por encima de todas estas funciones, determinados obsequios podían ser porta-dores de unos mensajes más sutiles y profundos: los caballos, como símbolos del buen gobierno e imprescindibles para la educación del príncipe; las armas, como exponentes del ejercicio militar y del poder del rey; y los retratos y medallas reales, como manifestación del linaje y como expresión de la autoridad, poder y grandeza de la Casa de Austria ante las cortes europeas.

${ }^{122}$ Sobre este tema puede consultarse también M. CANO CUESTA, Catálogo de medallas españolas, Madrid, 2005.

${ }^{123} \mathrm{M}$. del R. CASTO, “Una serie de medallas de virreyes de Nápoles", Hispania, 24, 1946, pp. 383-408. G. FINALDI, "Ribera, the Viceroys de Napoles and the King. Some observations on their Relations", en J. L. COLOMER (dir.), Op. cit., pp. 382-383. 